\title{
Micronucleus Test in Exfoliated Buccal Cells from Chromium Exposed Tannery Workers
}

\author{
Sudha Sellappa, Shibily Prathyumnan, Shyn Joseph, and Kripa S Keyan
}

\begin{abstract}
Our aim was to investigate the adverse effects of occupational exposure to trivalent chromium in tannery workers and unexposed persons. Trivalent chromium used in tanning industry is an environmental contaminant that acts as a carcinogen towards humans and animals. The carcinogenic potential of metals is a major issue in defining human health risk from exposure. In the present investigation, 84 tannery workers and 52 control subjects with similar mean ages, smoking prevalences and alcohol consumption were enrolled for DNA damage analysis in buccal cells by Micronucleus assay (MN). Workers showed a significant increase in micronucleated cells when compared to controls with respect to their smoking habits, alcohol consumption, age and years of exposure. The current study suggests that chronic occupational exposure to Chromium during tanning could lead to increased levels of DNA damage. The results of the present investigation are in agreement with those obtained with the same $\mathrm{Cr}$ (III) compounds in mutagenicity assays in bacteria and carcinogenicity tests in rodents. A re-evaluation of the mechanisms of chromium carcinogenisis is proposed.
\end{abstract}

Index Terms - genotoxicity, micronucleus, tannery workers, trivalent chromium.

\section{INTRODUCTION}

Chromium is one of the most widely used industrial metals in an array of industries such as pigment production, chrome plating, stainless steel welding and leather tanning [19, 4].

Chromium exists in its two stable oxidation states +3 and +6 [19]. Elemental chromium (0) does not occur naturally on earth. Commercial applications of chromium compounds include tanning (III), corrosion inhibition, plating, glassware-cleaning solutions, wood preservatives (VI), manufacture of safety matches, metal finishing (VI), and the production of pigments (III, VI) [4].

Leather tanning is the process of converting raw hides of skins into leather. Tanning is essentially the reaction of

Manuscript received March 15, 2011

Dr.Sudha Sellappa is an Associate Professor at the Department of Biotechnology, Karpagam University, Coimbatore, Tamilnadu, India (corresponding author phone: +91-422- 2611146; fax: +91-422-2611043e-mail: sudhasellappa@gmail.com).

Shibily Prathyumnan is a research scholar at the Department of Biotechnology, Karpagam University, Coimbatore, Tamilnadu, India (corresponding author phone: +91-422- 2611146; fax: +91-422-2611043; e-mail: shibilyps@gmail.com).

Shyn Joseph is a research scholar at the Department of Biotechnology, Karpagam University, Coimbatore, Tamilnadu, India (corresponding author phone: +91-422- 2611146; fax: +91-422-2611043; e-mail: shynjoseph@gmail.com).

Kripa Subhadra Keyan is a research scholar at the Department of Biotechnology, Karpagam University, Coimbatore, Tamilnadu, India (corresponding author phone: +91-422- 2611146; fax: +91-422-2611043; e-mail: kripakeyan86@gmail.com). collagen fibers in the hide with tannins, chromium, alum or other chemical agents. Approximately $90 \%$ of all leather is produced by chrome tanning. Basic trivalent chromium compounds are used in the leather production as a chelating agent to stabilize collagen fibers in the animal skin, providing it with the known thermal and hydro resistance of leather. Chrome tanning is still the most economically advantageous method to produce good quality leather. The heaviest metal exposure occurs in the workplace among occupationally exposed groups. A person spends, on average, one-third of his life at his workplace and therefore the environment in which he works can be a major factor in determining health.

Chromium has been recognized as one of the most effective tanning agents and has been widely employed in the leather industry since its discovery more than 100 years ago. Since then, some $85 \%$ of the leather produced worldwide is tanned with chromium salts, either alone or in combination with other tanning agents. Chrome-tanned leather tends to be softer and more pliable than vegetable tanned leather. Chrome tanning is cost-effectively beneficial and provides superior leather, and is not likely to be replaced by the existing alternative tanning agents in the near future.

There are several potential sources of air emissions in the leather tanning and finishing industry such as chromium emissions that may occur from chromate reduction, handling of basic chromic sulfate powder and from the buffing process. $\mathrm{Cr}$ and $\mathrm{Cr}$ compounds have been tested for genotoxicity in a variety of short-term tests using different end-points [28, 29, 16]. Moreover, there are reports on positive genotoxic effects in populations exposed to $\mathrm{Cr}[9,30,25,3,11]$. Workers occupationally exposed to $\mathrm{Cr}$ are considered to be at an elevated risk for developing cancer $[27,13]$.

Basic chromium (III) sulfate $\left[\mathrm{Cr}(\mathrm{H} 2 \mathrm{O})_{5}(\mathrm{OH}) \mathrm{SO}_{4}\right]$ is widely used in the leather industry as a chelating agent [7]. The minimum amount of chromium necessary to perform a good tanning is approximately $3 \mathrm{~g}$ of $\mathrm{Cr}_{2} \mathrm{O}_{3}$ for $100 \mathrm{~g}$ of leather. The nature of the salt of chromium present is also an important factor of absorption and toxicity. Chromium may enter the body by breathing, eating and by direct cutaneous contact, therefore, the tannery workers are exposed to this element, mainly in the inorganic $\mathrm{Cr}$ (III) form, or in the protein bound form (leather dust).

Sensitivity to trivalent compounds is much less frequent, but some workers may react to high concentrations of these compounds. Occupational exposure represents the main source of human contamination by chromium. Early identification of hazards is crucial to reduce exposure and carcinogenic risk. Exposure to chromium and other particles is a considerable hygiene problem in leather tanning related operations.

The present study aimed to investigate the genotoxic effects associated with occupational exposure to $\mathrm{Cr}$ (III) on South Indian tannery workers using the Micronucleus Assay 
(MN Assay). This test allows the detection of both clastogenic and aneugenic agents. The use of the MN test in exfoliated cells has substantially increased as it is considered a useful biomarker of genotoxic effects in populations exposed to genotoxicants [26].

The influence of confounding factors like age, smoking, alcohol drinking, duration of exposure on the differences in DNA damage was also analyzed. Although it is well established that tobacco smoking causes lung cancer, cancer at other sites and several other adverse health effects; less information is available concerning the outcome of combined exposure to cigarette smoke (CS), and other agents [1]. As chromium belongs to a family of wide spread metals, it could be impossible to eliminate it completely from the human environment and hence there is a need to analyze its genotoxic effects. The present study analyzed the synergistic genotoxic effect of smoking and alcohol consumption among tannery workers exposed to trivalent chromium with a view to provide more information on possible health effects of chromium in tannery workers.

\section{MATERIALS AND METHODS}

\section{A. Study Subjects}

Buccal cell samples were obtained from full-time tannery workers $(n=84)$ directly involved in the chrome tanning process. We collected buccal cells from control individuals $(n=52)$ not known to be exposed to either environmental or occupational carcinogens. The experimental and control groups was further branched as smokers (64 and 28), non-smokers (20 and 24), alcoholics (57 and 27) and non-alcoholics (27 and 25) respectively. The subjects who smoked $>5$ cigarettes/day at least for 1 year were considered as smokers and those who consumed $>120 \mathrm{gm}$ of alcohol/day were considered as alcoholics in both groups. Individual questionnaires were filled by all subjects, the questionnaire covered standard demographic questions (age, genetic disorders, number of X-ray diagnoses, vaccinations, medication, smoking, alcohol, etc.) and occupational questions (years of exposure). We ensured that the workers and the controls did not markedly differ from each other except for occupational exposure. We also ensured that all the subjects had not been taking any medicines nor had they been exposed to any kind of radiation for 12 months before sampling. The workers and control subjects were informed of the objectives of the work, and gave expressed informed and written consent to participate in this study before the collection of buccal cell sample. The samples of buccal cells were coded and the anonymity of the workers and control population was guaranteed. The institutional ethical committee approved the research procedures used in this study. The study was conducted in accordance with the principles for human experience as defined by the Helsinki Declaration.

\section{B. Cell Sampling and Preparation}

Buccal cells (BCs) were collected from consented volunteers at the end of the work shift according to the criteria established by Tolbert et al [24]. Prior to BC collection the mouth was rinsed thoroughly with water to remove any unwanted debris. Buccal cell samples were obtained by rubbing the inside of both cheeks using an extra soft tooth brush. The cells were collected in tubes containing $3 \mathrm{ml}$ sterile saline.

\section{Micronucleus Assay}

The MN test was carried out on buccal epithelial cells of 84 workers and 52 controls, selected randomly from the total number of subjects, according to the method of Rajeswari et al [22]. Exfoliated epithelial cells, which are continuously in contact with the environment, can be easily collected and rapidly analyzed and are therefore a very appropriate cell system for the study of the effects of mutagenic pollutants. Prior to buccal cell sampling the experimental and control groups were advised to rinse their mouth thoroughly with water to remove unwanted debris.

Buccal cells were obtained by gently rubbing the inside of both cheeks with an extra soft tooth brush for $1 \mathrm{~min}$ each. The participant then rinsed the mouth with $20 \mathrm{ml}$ of $0.9 \%$ saline and expectorated into a 50-ml conical-based tube. The buccal mucosa was transferred into Eppendorf tubes with Phosphate Buffered Saline (PBS) at pH. 7.0 and centrifuged for $10 \mathrm{~min}$ at $1500 \mathrm{rpm}$. Supernatant was removed and replaced with 5 $\mathrm{ml}$ of fresh PBS solution and centrifuged for $10 \mathrm{~min}$ at 1500 $\mathrm{rpm}$. This process was repeated thrice, as the PBS helps to inactivate endogenous, DNAases and aid in removing bacteria that may complicate scoring. After discarding the supernatant the pellet was smeared on to clean microscopic slides, air dried for $10 \mathrm{~min}$, and then fixed in cold methanol: acetic acid (3:1) for $10 \mathrm{~min}$. Slides were air dried for 10 to 15 min and stained in $2 \%$ Giemsa for $10 \mathrm{~min}$ and rinsed with double distilled water, air dried and viewed under a light microscope. A total of 2000 cells per individual were scored for analysis of micronuclei.

The following criteria for $\mathrm{MN}$ analysis were used in oral epithelial cells. An MN (1) must be less than one third the diameter of the main nucleus; (2) must be on the same focal plane; (3) must have the same color, texture, and refraction as the main nucleus; (4) must have a smooth oval or round shape; and (5) must be clearly separated from the main nucleus.

\section{Statistical Analysis}

The samples were coded at the time of preparation and scoring. They were decoded before statistical analysis for comparison. Mean and standard deviation (SD) were calculated for biomarker. The significance of the differences between control and worker end-point means were analysed using Student's t-test, whereas simple and multiple linear regression analyses were performed to assess the association between end-points and the independent variables. All calculations were performed using Windows statistical package, version 11.5 (IL, USA). Mean values and standard deviations were computed for the scores and the statistical significance $(\mathrm{P}<0.05)$ of effects (exposure, smoking, alcohol and age) was determined using analysis of variance (ANOVA).

\section{RESULTS}

The distribution of subjects with respect to age, smoking, alcohol consumption and years of exposure is given in Table I. The two groups studied had similar demographic characteristics. 


\section{A. Micronucleus Frequency in Buccal Cells}

The frequency of micronuclei (MN) was studied in 84 workers and in 52 controls. Workers revealed a significant induction of $\mathrm{MN}$ when compared with controls ( 7.19 vs. 4.03) (Table I). Individuals of the exposed as well as control groups with smoking habit and alcohol consumption showed an enhanced frequency of micronuclei (11.85 and 12.05) vs. (5.75 and 6.59) when compared to non smokers and non alcoholics (6.45 and 6.29) vs. (2.87 and 2.88). Workers who are smokers and alcoholics showed a highly significant increase $(\mathrm{p}<0.05)$ in $\mathrm{MN}$ frequency when compared to all other groups and subgroups (Table 1).An increase in $\mathrm{MN}$ frequency with an increase in duration of exposure was observed in workers (11.02 versus 9.12) (Table II). An age-dependent increase in MN frequency was also noted both in controls and exposed (2.61 vs. 2.04 and 6.85 vs. 5.12) (Table II).

\section{DISCUSSION}

The extensive use of chromium in industrial settings has elicited concern over the safety of workers and surrounding population. The trivalent form of chromium which is extensively used in leather tanning may directly react with the genetic material and has also been shown to generate oxidative damage in vitro. Although The International Agency for Research on Cancer has not evaluated chromium (III) compounds as potential carcinogenic agents for humans [14], the risk involved in chronic exposure is uncertain.

The toxicity of chromium $(\mathrm{Cr})$ in occupational settings has been essentially focused on the hexavalent form of the metal, a Group 1 known human carcinogen according to IARC (International Agency for Research on Cancer) classification. Nevertheless, hexavalent chromium has no toxic action until it is reduced inside the cell to lower oxidation states, the most stable being the trivalent form, $\mathrm{Cr}$ (III). Therefore, the $\mathrm{Cr}$ (III) may be the ultimate intracellular toxicant.

The hexavalent form is regarded as the primary toxic threat, due to its easy passage through biological membranes in contrast with the trivalent form, considered quite less toxic due to less efficient membrane passage. Nevertheless, trivalent chromium absorption has been demonstrated in workers exposed to this valence state, which indicates that the rate of uptake of $\mathrm{Cr}$ (III) by the cells may be slower, but effective in chronic occupational exposure settings. Organic complexes of trivalent chromium are absorbed to a greater extent than inorganic compounds, due to a better solubility in biological membranes.

For some occupations involving trivalent chromium exposure, increased risks for some cancers have been suggested, but the epidemiological data do not permit discrimination between effects due to hexavalent chromium or other carcinogenic agents in simultaneous exposures. A study on chromate production workers found that trivalent chromium showed no association with an increased risk of lung cancer, when adjusted for hexavalent chromium exposure and smoking [13]. Studies of other occupational exposure to hexavalent and trivalent chromium found increased risk of lung cancer, but the studies did not discriminate between hexavalent and trivalent exposure.
There are no reliable data for the settling of tolerable daily intake for oral exposure; therefore, no sample risk characterization for oral exposure can be done.

Cytogenetic biomarkers are the most frequently used end point in human biomonitoring studies and are used extensively to assess the impact of environmental, occupational and medical factors on genomic stability.

Present study reports an elevated $\mathrm{MN}$ frequency among $\mathrm{Cr}$ (III) exposed south Indian tannery workers. The current analysis suggests that tannery workers under their particular conditions of exposure (tobacco smoke and alcohol) reveal clear evidence of genotoxicity in buccal epithelial cells when evaluated by $\mathrm{MN}$ test. Previous investigations reporting genotoxic effects in workers of tanning industry using the $\mathrm{MN}$ test are scanty. Our study revealed a significant induction of $\mathrm{MN}$ in workers when compared to controls with respect to their age and years of exposure.

A clear increasing trend in $\mathrm{MN}$ incidence was evident in a large study designed specifically to assess the effect of ageing on chromosome damage [2]. Bukvic et al [21] also demonstrated a strong correlation between age and $\mathrm{MN}$ frequency and suggested that chromosome loss is a determining factor in this increase. Although the link between smoking and cancer is strong and exposure to genotoxic carcinogens present in tobacco smoke has been convincingly demonstrated $[15,12]$, and the same convincing association is apparent when assessing biomonitoring studies of genotoxicity.

Fenech [18] showed that, after adjustment for age and sex, individuals with high cigarette usage [17] had statistically greater $\mathrm{MN}$ compared to non-smokers. The evidence regarding an effect of drinking alcoholic beverages on increased $\mathrm{MN}$ is inconclusive. An increase in $\mathrm{MN}$ has been observed in alcoholics consuming alcoholic beverages but not in abstainers of a year or more $[6,8]$.

Chromium causes a variety of DNA lesions such as DNA strand breaks, SCEs and mutations [28, 10, 23, 29]. The oxidation state is the most important parameter for chromium toxicity. Cases of nasal cancer were also reported among these workers, exposed to a variety of forms of chromium, including $\mathrm{Cr}$ (VI) and $\mathrm{Cr}$ (III) compounds.

Tanning industry workers were found to have excessive incidence of lung and upper respiratory tract cancer [5] and other types of cancer like soft tissue sarcoma, gastro-intestinal and bladder cancer [20, 31]. Chromosome breakage (clastogenic events) is caused by DSB induced either directly or by the conversion of a SSB into a DSB after cell replication. A significant proportion of induced micronuclei may be the result of aneugenic effects of metals. Micronuclei results either from lesions/adducts at the level of DNA or chromosomes, or at the level of proteins directly or indirectly involved in chromosome segregation.

Therefore our results demonstrate that $\mathrm{MN}$ assay performed in exfoliated buccal mucosa cells is an ideal methodology to measure potential risk related to $\mathrm{Cr}$ (III) exposure. However, the results of this study are not enough to establish any causal connection, although there is experimental evidence that supports the genotoxicity of $\mathrm{Cr}$ (III). The results from one investigation in a specific occupational setting cannot be used to judge the genotoxic potential in another occupational setting. Hence, there is a need to evaluate different populations and to analyze different genotoxic parameters. Also, the possibility of 
unrecognized confounding factors is inevitable in studies such as this.

Workers in many occupational settings are exposed to certain genotoxic agents. These workers may not be aware that they have been exposed to genotoxic agents nor do they know the type and amount of agent to which they have been exposed. Therefore, there is a need to educate those who work with heavy metals about the potential hazard of occupational exposure and the importance of using protective measures. Since trivalent chromium may carry a risk to human health, it should be used more carefully and further investigation on the same is recommended.

TABLE I. FREQUENCY OF MiCRONUClEI WITH RESPECT TO SMOKING HABIT AND ALCOHOL CONSUMPTION IN CONTROL AND TANNERY WORKERS

\begin{tabular}{|c|c|c|c|c|c|c|c|c|}
\hline & Characterist & & $\begin{array}{l}\text { Sample } \\
\text { size }\end{array}$ & Age(years) & $\begin{array}{c}\text { Exposure } \\
\text { duration (years) }\end{array}$ & $\begin{array}{c}\text { No. of } \\
\text { Cigarettes/d }\end{array}$ & Alcohol & $\mathbf{M N}(\mathbf{M} \pm \mathbf{S D})$ \\
\hline & Total & & 52 & $37.63 \pm 8.44$ & - & - & - & $4.03 \pm 1.65$ \\
\hline & & Yes & 28 & $38.03 \pm 7.53$ & - & $9.17 \pm 2.49$ & - & $5.75 \pm 1.40^{*}$ \\
\hline$\varrho$ & & No & 24 & $36.45 \pm 8.28$ & - & - & - & $2.87 \pm 0.78$ \\
\hline$\frac{0}{n}$ & Alcohol & Yes & 27 & $34.55 \pm 8.10$ & - & - & $\begin{array}{c}195.55 \pm \\
44.77\end{array}$ & $6.59 \pm 1.15^{*}$ \\
\hline & & No & 25 & $36.52 \pm 8.22$ & - & - & - & $2.88 \pm 0.83$ \\
\hline & Total & & 84 & $37.48 \pm 8.60$ & $18.03 \pm 8.31$ & - & - & $7.19 \pm 1.15^{*}$ \\
\hline & & Yes & 64 & $38.23 \pm 8.19$ & $18.81 \pm 6.31$ & $9.21 \pm 2.29$ & - & $11.85 \pm 2.06^{*}$ \\
\hline 武 & & No & 20 & $36.5 \pm 9.32$ & $14.65 \pm 8.38$ & - & - & $6.45 \pm 1.19$ \\
\hline 2 & Alcohol & Yes & 57 & $39.71 \pm 8.08$ & $19.17 \pm 8.49$ & - & $\begin{array}{c}196.31 \pm \\
40.78\end{array}$ & $12.05 \pm 2.10 *$ \\
\hline & & No & 27 & $35.89 \pm 9.44$ & $15.70 \pm 8.51$ & - & - & $6.29 \pm 1.13$ \\
\hline
\end{tabular}

$* \mathrm{p}<0.05$

TABLE II. FREQUENCY OF MICRONUCLEUS WITH RESPECT TO DURATION OF EXPOSURE AND AGE IN CONTROLS AND TANNERY WORKERS

\begin{tabular}{|c|c|c|c|c|c|}
\hline & & \multicolumn{2}{|c|}{ Control $(n=52)$} & \multicolumn{2}{|c|}{ Exposed $(n=84)$} \\
\hline \multicolumn{2}{|c|}{ Characteristics } & & MN frequency & & MN frequency \\
\hline \multirow{2}{*}{ 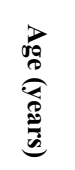 } & $<35$ & 21 & $2.04 \pm 0.04$ & 38 & $5.12 \pm 1.10$ \\
\hline & $\geq 35$ & 31 & $2.61 \pm 0.15^{*}$ & 46 & $6.85 \pm 1.23^{*}$ \\
\hline \multirow{2}{*}{ 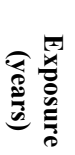 } & $<15$ & - & - & 32 & $9.12 \pm 2.02$ \\
\hline & $\geq 15$ & - & - & 52 & $11.02 \pm 1.57^{*}$ \\
\hline
\end{tabular}

$* \mathrm{p}<0.05$

\section{CONCLUSION}

Our findings conclude that chromium exposure causes instability of the genetic material in the workers and can be taken as an indication that these individuals have increased cancer risks. To enable a better assessment of the relative importance of dermal versus inhalation exposure, further quantitative data on uptake of chromium dust via the skin would be needed. Quantitative data on dermal uptake of chromium among exposed workers, relative to the inhalatory dose will enable a health risk assessment. This would require well-designed field studies with small groups of exposed workers either (i) solely skin exposed or (ii) solely with inhalation and (iii) a group with both dermal and inhalatory exposure. The body dose would need to be assessed with 
different biomarkers of exposure.

\section{ACKNOWLEDGEMENT}

The authors are grateful to the authorities of Karpagam University and Dr. K Sasikala, Unit of Human Genetics, Department of Zoology, Bharathiar University for their open handed support and encouragement. We also thank the volunteers of the study for their cooperation.

\section{REFERENCES}

[1] A. Hedenstedt, D. Jenssen, and B. M. Lidestein, "Mutagenicity of fume particles from stainless steel welding", Scand J Work Environ Health, vol. 3, pp. 203-211, 1977.

[2] C. Bolognesi, C. Lando, A. Forni, E. Landini, R. Scarpato, L. Migliore, and S. Bonassi, "Chromosomal damage and ageing: effect on micronuclei frequency in peripheral blood lymphocytes", Age Ageing, vol. 28, pp. 393-397, 1999.

[3] D. Benova, V. Hadjidekova, R. Hristova, T. Nikolova, M. Boulanova, I. Georgieva, M. Grigorova, T. Popov, T. Panev, and R. Georgieva, (2002) "Cytogenetic effects of hexavalent chromium in Bulgarian chromium platers", Mutat. Res., vol. 514, pp. 29-38, 2002.

[4] D. G. Barceloux. "Chromium”, J. Toxicol. Clin. Toxicol., vol. 37, pp. 173-194, 1999

[5] D.H. Garabrant and D.H. Wegman, "Cancer mortality among shoe and leather workers in Massachusetts", Am. J. Ind. Med., vol. 5, pp. 303-14, 1984.

[6] E. Castelli, P. Hrelia, F. Maffei, C. Fimognari, F. G. Foschi, F. Caputo, G. Cantelli-Forti, G. F. Stefanini, and G Gasbarrini, "Indicators of genetic damage in alcoholics: reversibility after alcohol abstinence", Hepatogastroenterology, vol. 46, pp. 1664-1668, 1999.

[7] E. L. Tavani, and C. Volzone, (1997) "Adsorption of Cr(III) from a tanning wastewater on kaolinite", J. Soc. Leather Technologists and Chemists, vol. 81, pp. 143-148, 1997.

[8] F. Maffei, G. C. Forti, E. Castelli, G. F. Stefanini, S. Mattioli, P. Hrelia, "Biomarkers to assess the genetic damage induced by alcohol abuse in human lymphocytes", Mutat. Res., vol. 514, pp. 49-58, 2002.

[9] F. Sarto, R. Tomanin, L. Giacomelli, G. Iannini, and A. R. Cupiraggi. "The micronucleus assay in human exfoliated cells of the nose and mouth: application to occupational exposures to chromic acid and ethylene oxide", Mutat. Res., vol. 244, pp. 345-351, 1990.

[10] F.Y. Wu, F.J. Tsai, H.W. Kuo, C.H. Tsai, W.Y. Wu, R.Y. Wang, and J.S. Lai, "Cytogenetic study of workers exposed to chromium compounds", Mutation Research, vol. 464, pp. 289-296, 2000.

[11] G. Quievryn, E. Peterson, J. Messer and A. Zhitkovich, "Genotoxicity and mutagenicity of chromium(VI)/ascorbate generated DNA adducts in human and bacterial cells", Biochemistry, vol. 42, pp. 1062-1070, 2003.

[12] H. F. Stich, W. Stich, and B. B. Parida. "Elevated frequency of micronucleated cells in the buccal mucosa of individuals at high risk for oral cancer: betel quid chewers", Cancer Lett., vol. 17, pp. 125-134, 1982.

[13] H. J. Gibb, P. S. Lees, P. F. Pinsky, and B. C. Rooney, "Lung cancer among workers in chromium chemical production", Am. J. Ind. Med., vol. 38, pp. 606-610, 2000.
International Agency for Research on Cancer, "IARC Monographs on the Evaluation of the Carcinogenic Risk of Chemicals to Humans, Chromium, Nickel and Welding”, IARC, Lyon, vol. 49, pp. 213-214, 1990.

[14] International Agency on Research on Cancer. IARC Monographs on the Evaluation of Carcinogenic Risks to Humans. Lyon: IARC; 2002.

[15] K. Kusal Das. "A comprehensive review on nickel (II) and chromium VI toxicities - possible antioxidant (Allium sativum Linn) defences", Am. J. Med. Sci., vol. 2, pp. 43 -50, 2009.

[16] M. Fenech, "Cytokinesis-block micronucleus cytome assay", Nat. Protoc., vol. 2, pp. 1084-1104, 2007.

[17] M. Fenech, "The cytokinesis-block micronucleus technique: a detailed description of the method and its application to genotoxicity studies in human populations”, Mutat. Res., vol. 285, pp. 35-44, 1993.

[18] M.D. Cohen, B. Kargacin, C.B. Klein, and M. Costa, "Mechanisms of chromium carcinogenicity and toxicity", Crit. Rev. Toxicol., vol. 23, pp. 255-281, 1993.

[19] M.H. Sweeney, J. Walrath, and R.J. Waxweiler "Mortality among retired fur workers. Dyers, dressers (tanners) and service workers", Scand. J. Work Environ. Health., vol. 11, pp. 257-64, 1985.

[20] N. Bukvic, M. Gentile, F. Susca, M. Fanelli, G. Serio, L. Buonadonna, A. Capurso, and G. Guanti, "Sex chromosome loss, micronuclei, sister chromatid exchange and aging: a study including 16 centenarians", Mutat. Res., vol. 498, pp. 159-167, 2001.

[21] N. Rajeswari, Y. R. Ahuja, U. Malini, S. Chandrashekar, N. Balakrishna, K. V. Rao, and Ashok Khar, "Risk assessment in the first degree female relatives of breast cancer patients using the alkaline comet assay", Carcinogenesis, vol. 21, pp. 557-561, 2000.

[22] N.J. Hodges, B. Adam, A.J. Lee, H.J. Cross, and J.K. Chipman, "Induction of DNA-strand breaks in human peripheral blood lymphocytes and A549 lung cells by sodium dichromate: association with 8-oxo-2-deoxyguanosine formation and inter-individual variability", Mutagenesis, vol.16, pp. 467-474, 2001.

[23] P. E. Tolbert, C. M. Shy, J. W. Allen, "Micronuclei and other nuclear anomalies in buccal smears: methods development", Mutat. Res. vol. 271 pp. 69-77, 1992.

[24] R. R. Tice, "The single cell gel/comet assay: a microgel electrophoretic technique for the detection of DNA damage and repair in individual cells", in Enivironmental Mutagenesis, vol III, D. H. Phillips and S. Venitt, Eds. Bios Scientific Publishers, Oxford, UK, 1995, pp. 315-339.

[25] S. A. Salama, M. Serrana, and W. W. Au, "Biomonitoring using accessible human cells for exposure and health risk assessment", Mutat. Res., vol. 436, pp. 99-112, 1999.

[26] S. De Flora, "Threshold mechanisms and site specificity in chromium (VI) carcinogenesis", Carcinogenesis, vol. 21, pp 533-541, 2000.

[27] S. De Flora, M. Bagnasco, D. Serra, and P. Zanacchi, "Genotoxicity of chromium compounds, a review", Mutation Research, vol. 238, pp. 99-172, 1990.

[28] T. J. O' Brien, S. Ceryak, and S. R. Patierno. "Complexities of chromium carcinogenesis: role of cellular response, repair and recovery mechanisms", Mutat. Res., vol. 533, pp. 3-36, 2003.

[29] Y. J. Choi, Y. M. Kim, and C. W. Cha. "A study on sister chromatid exchanges in lymphocytes in some metal plating workers", Korea Univ. Med. J., vol. 24, pp. 249-257, 1987.

[30] Z. Mikoczy, A. Schütz, and L. Hagmar, "Cancer incidence and mortality among Swedish leather tanners", Occup. Environ. Med., vol. 51, pp. 530-5, 1994. 